http://dx.doi.org/10.4314/bajopas.v12i1.8

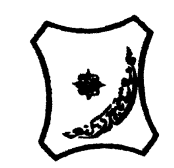

Bayero Journal of Pure and Applied Sciences, 12(1); 52 - 62

Received: May, 2018

Accepted: December, 2018

ISSN $2006-6996$

\title{
SEX AND AGE RELATED VARIATIONS IN SOMATOTYPE OF ETHNIC HAUSA ADOLESCENTS'FROM ZARIA, NORTH-WESTERN NIGERIA
}

\begin{abstract}
Mustapha, M $^{{ }^{*}}{ }$ Adamu, A. A. ${ }^{a, b}$, Dahiru, A. U. ${ }^{\text {a }}$, and Maryam, M. ${ }^{\text {a }}$
${ }^{a}$ Department of Human Anatomy, Faculty of Basic Medical Sciences, College of Health Sciences, Ahmadu Bello University Zaria, P. O. Box 2555, Zaria, Kaduna state, Nigeria

${ }^{b}$ Department of Radiology, Ahmadu Bello University Teaching Hospital, Zaria, Nigeria

*Corresponding author: M. Mustapha, Department of Human Anatomy, Faculty of Basic Medical

Sciences, College of Health Sciences, Ahmadu Bello University Zaria, P. O. Box 2555, Zaria, Kaduna state, Nigeria,+2340839297156, e-mail: mmustapha@abu.edu.ng

\section{ABSTRACT}

This study was aimed at investigating the somatotype characteristics of adolescent Hausa ethnic group of Zaria Local Government Area, Kaduna State, North Western Nigeria in the context of sex- and age- related variations. A total number of 384 apparent/y healthy adolescent subjects aged 10-19 years (187 males and 197 females) were random/y selected and somatotyped according to the protocol of Carter and Heath (1990). The somatotype component ratings, the somatotype attitudinal distance (SAD) and somatocharts were computed using the somatotype calculation and analysis software. A somatotype analysis of variance (SANOVA) which compares the somatotype of each group by using the somatotype attitudinal distances (SAD) within and between the groups was used to test the significance of gender differences. A MANOVA analysis was used to assess the significance of age differences in somatotypes. The mean somatotype was mesomorph ectomorph (1.68-2.31-3.75) for males and central for females (3.10-2.23-3.29). The females were more endomorphic than the males ( $F=240.47, P<0.001$ ) while the males on the other hand were more ectomorphic than the females ( $F=9.9, P=0.002)$. The mesomorphic component did not differ between the sexes ( $F=0.33, P=0.427$ ). The one-way MANOVA analysis indicated a significant effect of age on mean somatotypes in males, as well as in females.In conclusion, there were notable sex differences in the somatotypes of adolescents, with girls being significantly more endomorphic and boys being more ectomorphic. In both sexes, the somatotype showed significant changes from early adolescence to late adolescence. More studies, especially longitudinal ones, are necessary to better understand somatotype variations during adolescence.
\end{abstract}

\section{INRODUCTION}

A growth change in humans, especially during adolescence, is characterized by significant changes in body size, composition and shape (Kalichman and Kobyliansky, 2006), which can be better explained usingthe modus operandi of somatotype. A somatotype basically gives a gestalt summary of the overall body outlook in terms of the shape and composition independent of the body size (Carter, 1996). It has three basic components; endomorphy (fatness), mesomorphy (musculoskeletal development) and ectomorphy (leanness) (Carter and Heath, 2002). Among the different methods of obtaining somatotype, the Heath and Carter anthropometric somatotypeis now the most preferred in estimating the somatotype because studies have shown that this technique is highly reliable, simple, unique and feasible(Reis et al., 2007; Choi et al., 2013; Liivet al., 2013).

The changes in the somatotype components during growth in adolescents (defined as individuals between 10 and 19 years old [WHO, 2015])can provide vital information for understanding the growth patterns, the timing, and rate of sexual maturation (Toselli et al., 1997; Claessenset al., 2000). It can also provide information regarding adult physique variations and can be used to compare and contrast physique patterns between different populations and ethnic groups (Malinaet al., 2004). 
BAJOPAS Volume 12 Number 1, June, 2019

Several morphologists have documented the somatotype of Caucasian children and adolescents (Gakharand Malik 2002; Rahmawatiet al., 2004; KalichmanandKobyliansky, 2006; Bhasinand Jain 2007; Singh et al. 2007; ÖzenerandDuyar 2008). However, in Nigeria, the most populous Black Country with diverse multiethnic groups, such studies are generally sparse or absent.A somatotype study of Andibila children aged 7-14 year in Oju, Benue, North-Central Nigeria, by Goon et al. (2013) is one of the few, recent and most comprehensive so far. No information, to the best of our knowledge, is available on the somatotypes of adolescent Hausa ethnic group of Zaria Local Government Area, Kaduna State. Therefore, this study was aimed at investigating the somatotype characteristics of adolescent Hausa ethnic group of Zaria, North Western Nigeria in the context of sex- and age- related variations.

\section{MATERIALS AND METHODS}

Study Location

Zaria is a Hausa land in the northern part of Kaduna State, in the northern part of Nigeria and is located on latitude $11^{\circ} 04^{\prime}$ north and longitude $7043^{\prime}$ east. It is defined by a $15 \mathrm{~km}$ radius from the $\mathrm{PZ}$ post office (considered as the city centre) and is well connected by roads and rail with other regions of the country. Distances from Kaduna, Kano, Jos and Sokoto are approximately; 75 km, 176 km, 387 km and 404 $\mathrm{km}$ respectively. Zaria is the second principal town in Kaduna state after Kaduna metropolis, and is home to Ahmadu Bello University, established in 1962. It is also host to several other Federal Government Institutions, like Federal College of Education, National Institute for Transport Technology, Federal Institute of Chemical and Leather Research, Nigerian College of Aviation Technology and Industrial Development Corporation. The population of Zaria metropolis is approximately 975,153 (National Population Comission, 2006). It is made up of two Local Government Councils, Zaria Local Government, consisting of two districts; Zaria walled city and Tudun Wada, and Sabongari Local Government which consists of three districts; SabonGari, Samaru, and the Government Reservation Area.The economic life of Zaria people revolves around agriculture and rearing of cattles for sale and consumption. Staple diets of the people include cereals and seasonal vegetables.

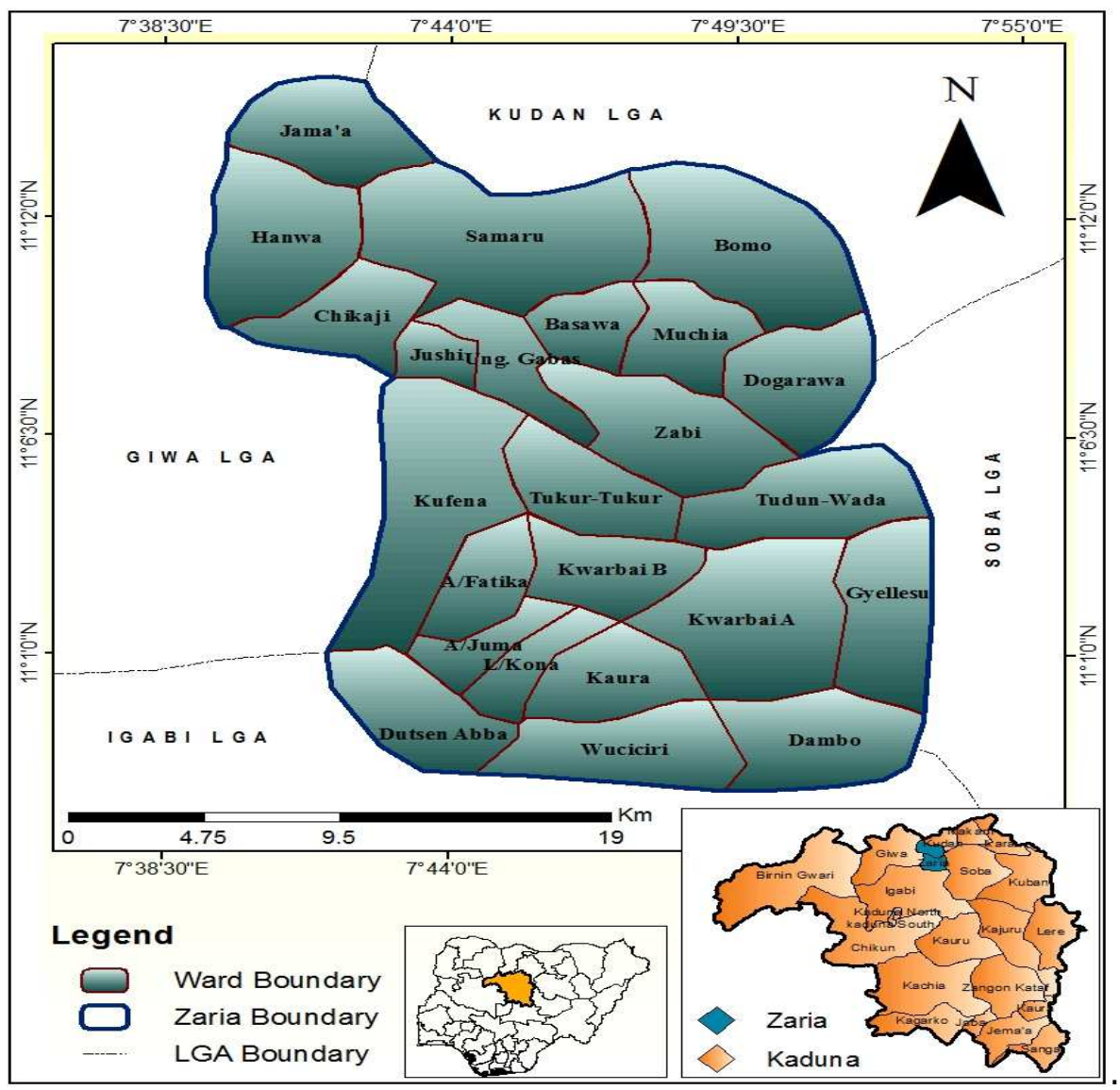

Figure 1: Map of Zaria Local Government (Quickbird $\_$2015) 


\section{Sample}

The study sample consisted of 384 Hausa (197 girls and 187 boys) adolescents aged $10-19$ years who were randomly selected and recruited for the study. Only the apparently healthy subjects present in the schools where the study population was drawn from at the time of the research(March to July 2017) were recruited for the study. Informed consent was obtained from the children's parents or guardians as the case may be and permission was obtained from the various schools concerned. The Ethics Committee on Human Research, Ahmadu Bello University Zaria endorsed the study protocol.

Data for the present investigation was collected from five differentsecondary schools in Zaria
metropolis.Information about the dates of birth of the subjects was obtained from the school records and the subjects were grouped into seven age groups, of one year each, using age mid-points as shown in table 1 . In each case, the following parameters were measured height, weight, biepicondylar breadth of the humerus and femur, contracted arm girth and calf girths, and skinfoldthicknesses (triceps, subscapular, medial calf and supraspinal). Standard anthropometric tools following the procedures as outlined by the International Society for theadvancement of kinanthropometry (ISAK) (2001) was employed for the data collection.

Table 1: Distribution of study population based on age.

\begin{tabular}{crrrrrrrrrrr}
\hline Age & 10 & 11 & 12 & 13 & 14 & 15 & 16 & 17 & 18 & 19 & Total \\
\hline Male & 2 & 2 & 8 & 22 & 17 & 29 & 32 & 36 & 23 & 16 & 187 \\
Female & 0 & 2 & 4 & 12 & 14 & 37 & 39 & 58 & 29 & 2 & 197 \\
\hline
\end{tabular}

\section{Statistical analysis}

The somatotype component ratings, the somatotype attitudinal distance (SAD) and somatocharts were computed using the somatotype calculation and analysis software (Carter and Heath, 2002). Descriptive statistics were calculated for height, weight, the three somatotype components, viz. endomorphy, mesomorphy, and ectomorphy. A somatotype analysis of variance (SANOVA) which compares the somatotype of each group by using the somatotype attitudinal distances (SAD) within and between the groups was used to test the significance of gender differences. Chi-square test was used to check for associations between somatotype categories based on sex. The significance of age differences in somatotypes was assessed with the help of MANOVA analysis that used Wilk's Lambda as test statistics (Cressieet al., 1986) with Scheffe's Post Hoc. All statistical analyses were performed with Statistical Product and Service Solutions (SPSS) version 23.0 and the significance level was set at $P<0.05$.

\section{RESULTS}

Tables 2 and 3 display the statistical details of height, weight, endomorphy, mesomorphy and ectomorphy for the adolescent Hausa boys and girls of Sabon Gari L.G.A., Kaduna state. It can be seen from the table and figure $2(A)$ and 3 (A) that height and weight showed a general increase with age. The maximum increase in height was noted from 11 to 12 years $(15 \mathrm{~cm})$ in girls and from 10 to 11 years in boys $(9 \mathrm{~cm})$. For weight, the maximum gain was recorded from 10 to 11 years $(12 \mathrm{~kg})$ in boys and from 11 to 12 years in girls $(14.5 \mathrm{~kg})$.

Figures 2 (B) and 3 (B) shows the age trends of the three somatotype components. As is evident from Table 2 and 3, the age trends of various somatotype components were variable, in both sexes. The mean ectomorphy among boys showed a marginal increase from 10 to 11 years, followed by a decreasing tendency from 11 to 19 years. On the other hand, in females, there was a general trend towards an increase in mean endomorphy with the advancement of age. In females, the mean endomorphy increased from 1.75 units at 11 years to 3.0 units at 13 years, thus recording a total gain of 1.25 units. Then a slight decrease at 14 years and thereafter an upward increasing trend was noticed.

The mean mesomorphy showed a rising and falling pattern in general in both sexes. In boys, the mean mesomorphy increased from 3.0 units at 10 years to 3.9 units at 11 years, thus recording a total gain of 0.9 units. It then decreased at 12 years and subsequently gradually rose up to the age of 15 years, then marginally decreased at 16 years and finally increased afterwards. In females, the mean mesomorphy, increased from 11 years to 12 years recording a gain of 1.7 units. At 13 years a slight fall was noticed and thereafter an increase. Ectomorphy in boys also showed a rising and falling trend. 
BAJOPAS Volume 12 Number 1, June, 2019

From 10 to 11 years, the boys showed an overall gain of 1.75 units in mean ectomorphy. Thereafter a decrease was observed at 12 years, then an increase at 13 years and it continued in this pattern to the age of 19 years. In girls, there was a clear trend towards a decrease in ectomorphy with age increase. From 15 to 19 years, the ectomorphy registered a total decline of 2.96 units in girls.

Table 2: Body height, weight and somatotype components of male subjects

\begin{tabular}{rrrcccc}
\hline \multicolumn{2}{c}{ Age Group } & Height $(\mathrm{cm})$ & Weight $(\mathrm{kg})$ & Endomorphy & Mesomorphy & Ectomorphy \\
\hline & \multicolumn{1}{c}{$\mathrm{n}$} & \multicolumn{1}{c}{ Mean \pm SD } & Mean \pm SD & Mean \pm SD & Mean \pm SD & Mean $\pm S D$ \\
10 & 2 & $151.00 \pm 1.41$ & $42.50 \pm 3.54$ & $1.65 \pm 0.35$ & $3.00 \pm 1.70$ & $3.15 \pm 1.20$ \\
11 & 2 & $142.00 \pm 0.00$ & $30.00 \pm 0.00$ & $1.25 \pm 0.35$ & $3.90 \pm 0.71$ & $4.90 \pm 0.00$ \\
12 & 8 & $148.13 \pm 6.88$ & $38.25 \pm 6.54$ & $1.65 \pm 0.44$ & $1.40 \pm 0.83$ & $3.74 \pm 0.91$ \\
14 & 22 & $149.23 \pm 10.73$ & $40.14 \pm 9.47$ & $1.74 \pm 0.68$ & $1.68 \pm 1.05$ & $3.52 \pm 1.12$ \\
15 & 17 & $151.00 \pm 12.03$ & $39.71 \pm 8.79$ & $1.30 \pm 0.38$ & $1.88 \pm 1.11$ & $4.01 \pm 1.61$ \\
16 & 32 & $153.03 \pm 9.73$ & $42.50 \pm 8.82$ & $1.72 \pm 0.83$ & $2.37 \pm 1.80$ & $3.78 \pm 1.82$ \\
17 & 36 & $159.81 \pm 6.49$ & $47.56 \pm 7.81$ & $1.50 \pm 0.47$ & $2.14 \pm 1.57$ & $3.85 \pm 1.37$ \\
18 & 23 & $166.85 \pm 4.19$ & $48.60 \pm 7.73$ & $1.95 \pm 0.94$ & $2.73 \pm 1.37$ & $4.08 \pm 1.29$ \\
19 & 16 & $167.13 \pm 3.93$ & $56.50 \pm 4.37$ & $1.70 \pm 0.32$ & $2.82 \pm 1.38$ & $3.28 \pm 0.88$ \\
\end{tabular}

SD: Standard deviation

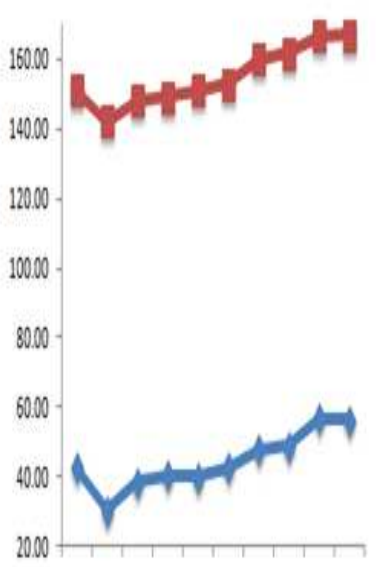

$10 \quad 11 \quad 12 \quad 13 \quad 14 \quad 15 \quad 16 \quad 17 \quad 1819$

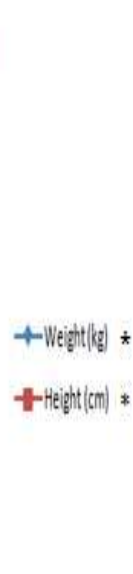

Agel(years)

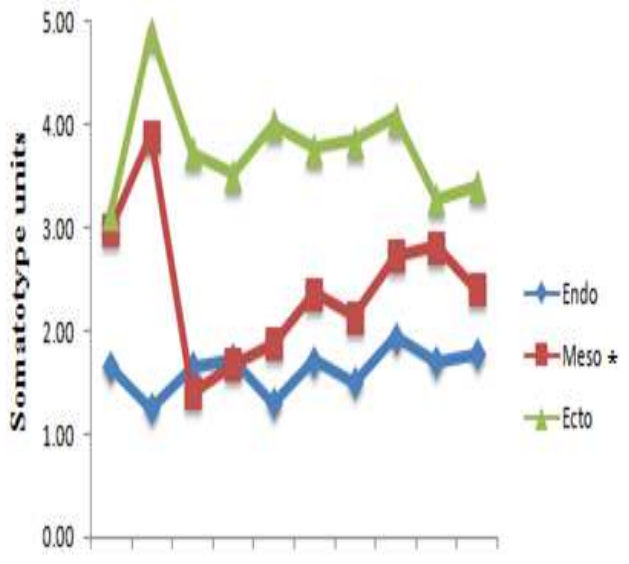

$\begin{array}{llllllllll}10 & 11 & 12 & 13 & 14 & 15 & 16 & 17 & 18 & 19\end{array}$

Age(Years)

A

Figure 2: $(\mathrm{A})$ Age trends in mean height $(\mathrm{Ht})$ and weight $(\mathrm{Wt})$ of the male subjects $(\mathrm{B})$ Age trends in mean endomorphy (Endo), mesomorphy (Meso) and ectomorphy (Ecto) of the male subjects $(* P<0.05)$

Table 3: Body height, weight and somatotype components of the female subjects

\begin{tabular}{rrrrccc}
\hline \multicolumn{2}{l}{ Age Group } & \multicolumn{1}{c}{ Height $(\mathrm{cm})$} & \multicolumn{1}{c}{ Weight $(\mathrm{kg})$} & Endomorphy & Mesomorphy & Ectomorphy \\
\hline & \multicolumn{1}{c}{$\mathrm{n}$} & \multicolumn{1}{c}{ Mean \pm SD } & \multicolumn{1}{c}{ Mean \pm SD } & Mean \pm SD & Mean \pm SD & Mean $\pm S D$ \\
11 & 2 & $142.50 \pm 0.71$ & $32.75 \pm 7.42$ & $1.75 \pm 1.06$ & $0.35 \pm 0.35$ & $4.20 \pm 2.69$ \\
12 & 4 & $157.50 \pm 13.40$ & $47.25 \pm 9.67$ & $2.13 \pm 0.73$ & $2.05 \pm 0.77$ & $3.40 \pm 0.91$ \\
13 & 12 & $152.42 \pm 6.36$ & $41.58 \pm 10.07$ & $3.00 \pm 0.88$ & $1.98 \pm 1.09$ & $3.88 \pm 1.41$ \\
14 & 14 & $152.79 \pm 4.44$ & $43.75 \pm 7.37$ & $2.45 \pm 0.76$ & $2.29 \pm 0.92$ & $3.33 \pm 1.37$ \\
15 & 37 & $156.41 \pm 4.84$ & $43.78 \pm 7.24$ & $2.83 \pm 1.01$ & $1.91 \pm 1.35$ & $4.11 \pm 1.56$ \\
16 & 39 & $158.12 \pm 6.69$ & $48.88 \pm 7.50$ & $3.38 \pm 0.99$ & $2.25 \pm 1.55$ & $3.24 \pm 1.44$ \\
17 & 58 & $157.60 \pm 6.51$ & $49.39 \pm 7.66$ & $3.25 \pm 1.10$ & $2.31 \pm 1.16$ & $3.04 \pm 1.43$ \\
18 & 29 & $156.59 \pm 5.23$ & $50.56 \pm 8.85$ & $3.37 \pm 1.17$ & $2.64 \pm 1.22$ & $2.64 \pm 1.39$ \\
19 & 2 & $161.50 \pm 0.71$ & $66.25 \pm 13.08$ & $3.20 \pm 1.41$ & $2.75 \pm 1.77$ & $1.15 \pm 1.48$ \\
\hline
\end{tabular}




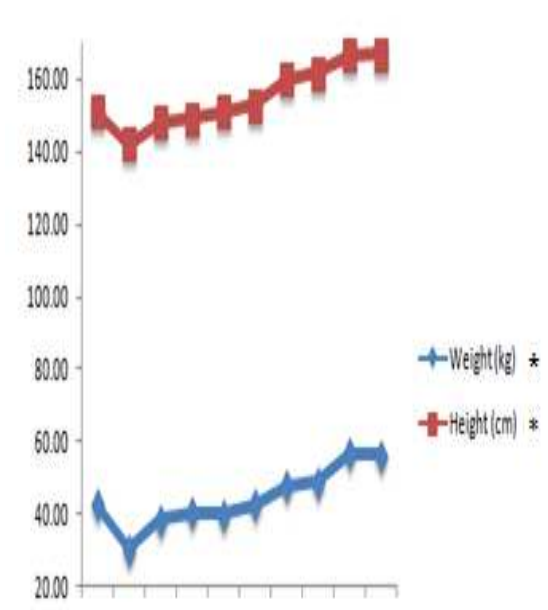

10.11 $12 \quad 13 \quad 14 \quad 15 \quad 16 \quad 17 \quad 18 \quad 19$

Age(veress)

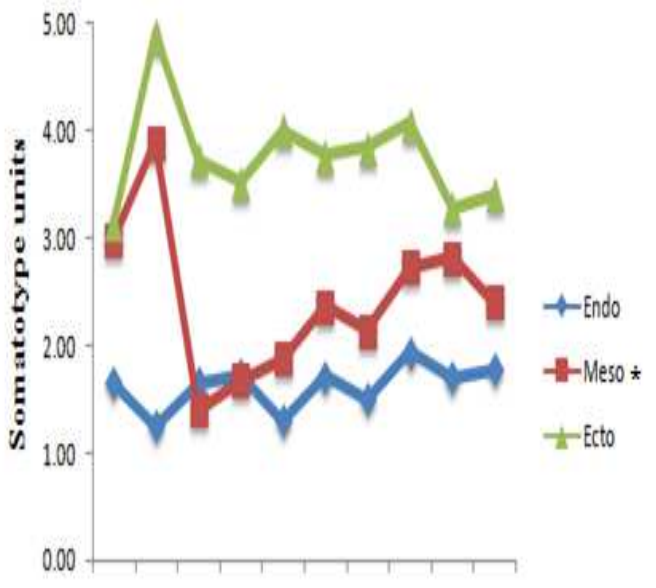

$\begin{array}{lllllllllll}10 & 11 & 12 & 13 & 14 & 15 & 16 & 17 & 18 & 19\end{array}$

Age (Years)

A

B

Figure 3: (A) Age trends in mean height $(\mathrm{Ht})$ and weight $(\mathrm{Wt})$ of the female subjects (B) Age trends in mean endomorphy (Endo), mesomorphy (Meso) and ectomorphy (Ecto) of the female subjects $(* P<0.05)$

Figure 4 is a somatochart showing the somatotype distribution of the study population based on sex. For the males, the mean age was 15.72 years and the majority of the somatotype means clustered on the South Eastern and North Eastern Axis of the boundary of the somatochart. Also, on the Somatochart, is the profile marker inside an empty circle which represents the mean somatotype for all the profiles in the document. Hence the mean

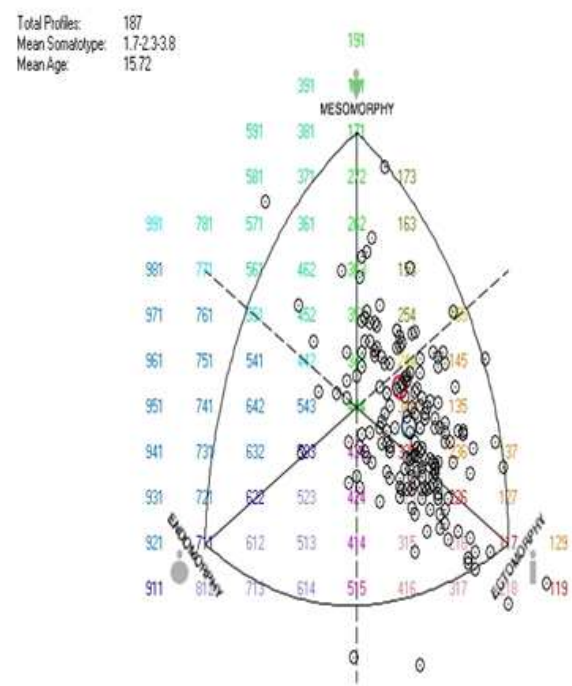

somatotype for all the male profiles was mesomorph-ectomorph (1.7-2.3-3.8). For the females on the hand, mean age was 15.56 years with the somatoype means clustering in nearequal proportionson the South Western, North Western, North Eastern and South Eastern Axis of the boundary of the somatochart. Thus, the mean somatotype for all the female profiles was central (3.1-2.2-3.3).

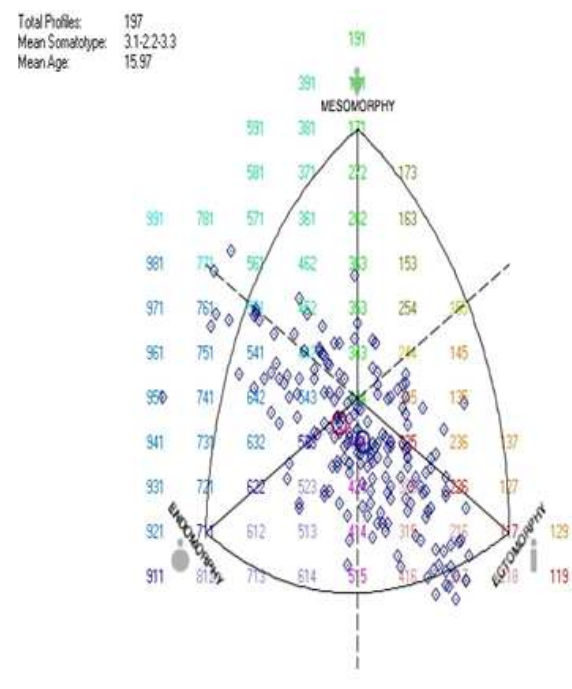

Figure 4: Somatotype distribution of the female and male subjects respectively 
BAJOPAS Volume 12 Number 1, June, 2019

The somatotype analysis of variance (SANOVA) table for the overallstudy population, which compares the somatotype of each group by using the somatotype attitudinal distances (SAD) within and between the groups, is presented in table 4. The males had a low endomorphic rating of 1.68 while the female on the other hand had a moderate endomorphic rating of 3.1.Both males and females had a low mesomorphic rating of 2.31 and 2.23 respectively (Table 4 ). The ectomorphic ratings for both males and females were moderate
(3.75 and 3.29 respectively) (Table 4). Therewas a statistically significant difference in the overall somatotypes of both male and female subjects $(\mathrm{F}=45.00, P<0.001)$ (Table 4). Also shown in table 5 , is a univariate analysis of the dominant somatotype component of males and females. The females were more endomorphic than the males ( $F=240.47, P<0.001)$ while the males on the hand were more ectomorphic than the females $(F=9.9, P=0.002)$ (Table 5). The mesomorphic component did not differ between the sexes ( $\mathrm{F}=0.33, P=0.427)$.

Table 4: Somatotype analysis of variance (SANOVA) for the female and male subjects

\begin{tabular}{cccc}
\hline Group & Frequency & Mean & Standard Deviation \\
\hline Male & 187 & $1.68-2.31-3.75$ & $0.66-1.44-1.34$ \\
Female & 197 & $3.10-2.23-3.29$ & $1.07-1.28-1.52$ \\
ANOVA & $\mathrm{F}=45.53$ & $P<0.001$ & \\
\hline
\end{tabular}

Table 5: Univariate analysis of variance of the individual somatotype componentsin both sexes

\begin{tabular}{lllll}
\hline Variable & DF-within & DF-between & F-ratio & p-value \\
\hline Endomorphy & 382.00 & 1.00 & 240.47 & $<0.001$ \\
Mesomorphy & 382.00 & 1.00 & 0.33 & 0.427 \\
Ectomorphy & 382.00 & 1.00 & 9.90 & 0.002 \\
\hline
\end{tabular}

In terms of the distribution of the subjects according to the regions in the somatocharts (Figure 5), ten major somatotype categories were found for the males: endomorph-ectomorph (7), balanced endomorph (1), mesomorph-endomorph (2), endomorphic mesomorph (4), balanced mesomorph (12), ectomorphic mesomorph (17), mesomorph-ectomorph (22), mesomorphic ectomorph (37), balanced ectomorph (80) and central (3). The females on the other hand hadtwelvecaetegories: endomorph-ectomorph (22), ectomorphic endomorph (10), balanced endomorph (9), mesomorphic endomorph (19), mesomorph-endomorph (17), endomorphic mesomorph (6), balanced mesomorph (3), ectomorphic mesomorph (2), mesomorph-ectomorph (3), mesomorphic ectomorph (14), balanced ectomorph (73) and central (22).

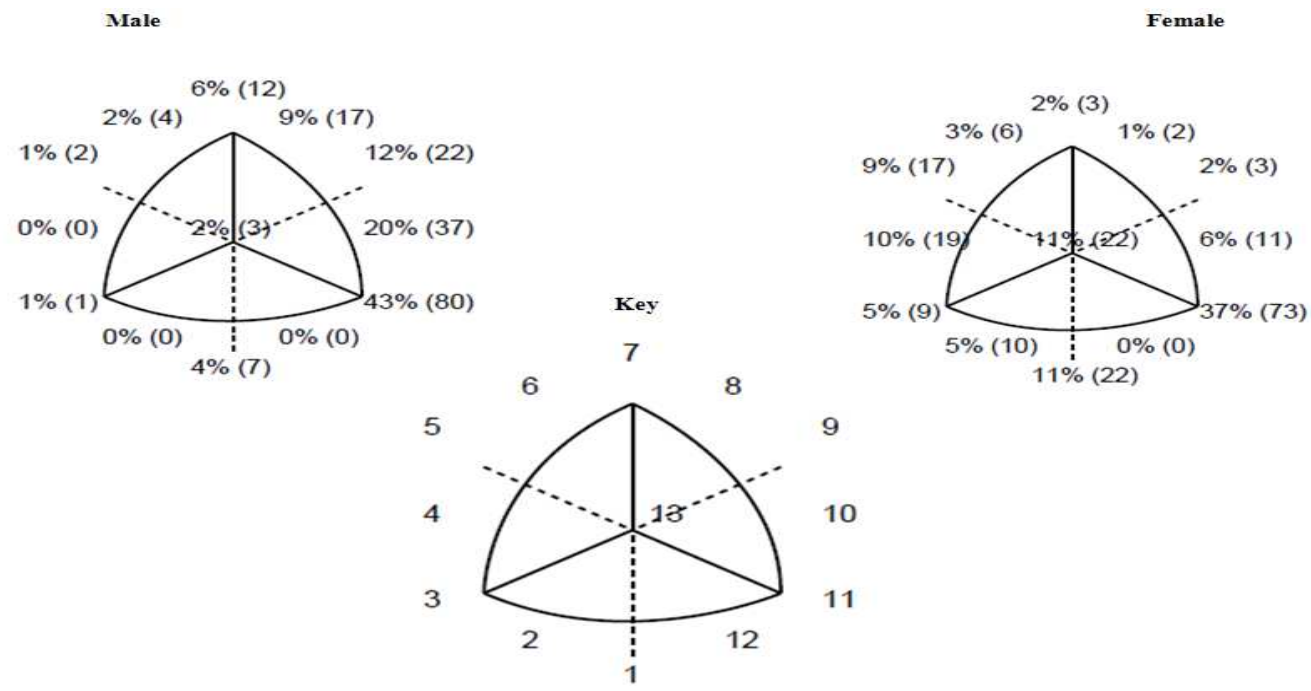

Figure 5: Category chart showing the percentage/frequency profile of the major somatotype categories based on sex (Keys: 1= endomorph-ectomorph; 2=ectomorphic endomorph; 3= balanced endomorph; 4= mesomorphic endomorph; 5= mesomorph-endomorph; 6= endomorphic mesomorph; 7= balanced mesomorph; 8= ectomorphic mesomorph; $9=$ mesomorph-ectomorph; 10= mesomorphic ectomorph; 11= balanced ectomorph; 12= endomorphic ectomorph; 13= central 


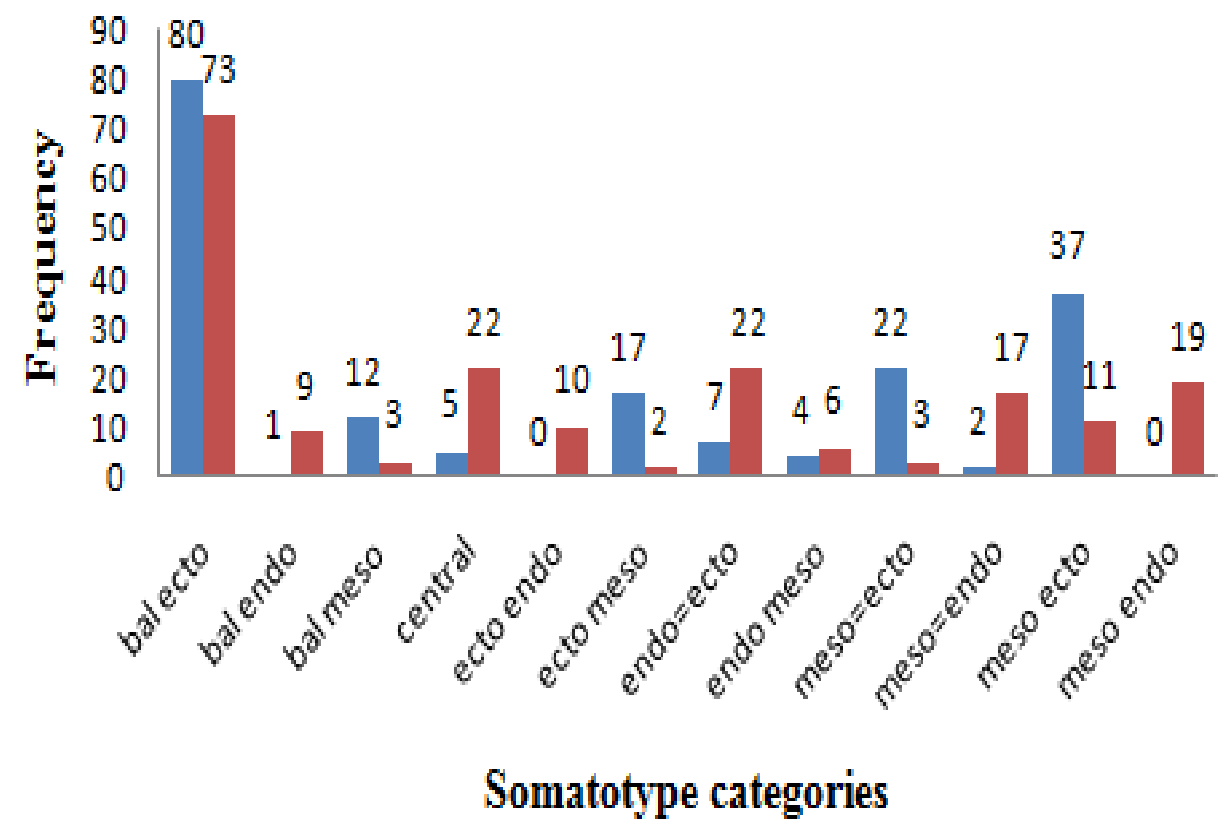

\section{- male female}

Figure 6 is a chart comparing the somatotypes categories according to the sex. There was a statistically significant association for male and female subjects $\left(X^{2}=112.001, P<0.05\right)$ based on the somatotype categories.

Figure 6: Comparison of somatotype categories according to sex $\left(x^{2}=112.001, P<0.001\right)$

Bal-Ecto: Balanced-Ectomorph; Bal-Endo:Balanced-Endomorph; Bal-Meso: Balanced-Mesomorph; Ecto-Meso: Ectomorphic-mesomorph; Endo-Meso: Endomorphic-Mesomorph; Meso=Ecto: Mesomorph Ectomorph; Meso-Ecto: Mesomorphic-Ectomorph; Endo-Meso:EndomorphicMesomorph;Endo=Ecto:Endomorph-Ectomorph; Meso=Endo:Mesomorphic-Endomorph; EctoEndo:Ectomorphic-Endomorph

To see the effect of age, according to sex, on various parameters, a MANOVA analysis with Scheffe's Post Hoc procedure was done. Tables 5 and 6 contain the results of the analysis. In the case of boys, the F-value $\left(F_{45}, 777\right)$ for the test (Wilk's Lambda $=0.424$ ) was 3.650 and Noncent parameter $=145.405$ which was highly significant $(P<0.05)$. In girls also, the $\mathrm{F}$-value of the test $\left(F_{40,806}\right)$ for the test (Wilk's Lambda $=$ 0.569 ) was 2.778 and Noncentparameter $=$ 96.044 which was highly significant $(P<0.05)$. Hence the MANOVA analysis has proven the significant effect of age on various parameters in boys, as well as in girls. The table also displays the F-values for the effect of age on various dependent variables. In the case of boys, the Fvalues for mesomorphy was significant $(P<0.05)$, indicating the significant effect of age. On the other hand, in the case of girls, the endomorphy and ectomorphy F-values were significant $(P<0.05)$, which suggests significant age influence on these two somatotype components. However, height and weight showed significant F-values $(P<0.05)$ in both sexes.

Scheffe's Post Hoc tests for multiple comparisons did not reveal significant differences between various age groups for endomorphy and ectomorphyexcept for mesomorphy (years) among boys. In boys Scheffe's Post Hoc tests revealed significant differences in mesomorphy between age groups 10 and 11 . Among the girls, Scheffe's Post Hoc tests revealed significant differences in endomorphy between age groups 11 and 13, and 14 and 16 years. As was the reverse case with boys, pairwise age comparisons of mesomorphy among girls were not significant for the majority of age groups. Scheffe's Post Hoc tests for multiple age comparisons in ectomorphy in girls were significant between 15 and 18 years. However, in boys as well as in girls, the differences were significant $(P<0.05)$ for height and weight for the majority of age groups. 
Table 6: Results of MANOVA analysis to see the effect of age on height, weight, endomorphy, mesomorphy and ectomorphy among male adolescent Hausa

\begin{tabular}{ccrrrrr}
\hline $\begin{array}{c}\text { Dependent } \\
\text { variable }\end{array}$ & $\begin{array}{c}\text { Wilks' } \\
\text { Lambda }\end{array}$ & $\mathrm{F}$ & $\mathrm{df}$ & Sig. & \multicolumn{1}{c}{$\begin{array}{c}\text { Noncent } \\
\text { parameter }\end{array}$} & $\begin{array}{c}\text { Observed } \\
\text { power }\end{array}$ \\
\hline Overall & 0.424 & $3.650^{*}$ & 45,777 & 0.001 & 145.405 & 1.000 \\
\hline Height $(\mathrm{cm})$ & - & $13.773^{*}$ & 9,177 & 0.001 & 123.960 & 1.000 \\
Weight $(\mathrm{cm})$ & - & $13.758^{*}$ & 9,177 & 0.001 & 123.823 & 1.000 \\
Endomorphy & - & 1.743 & 9,177 & 0.082 & 15.686 & 0.778 \\
Mesomorphy & - & $2.162^{*}$ & 9,177 & 0.027 & 19.455 & 0.875 \\
Ectomorphy & - & 1.034 & 9,177 & 0.415 & 9.305 & 0.504 \\
\hline
\end{tabular}

$* P<0.05$

Table 7: Results of MANOVA analysis to see the effect of age on height, weight, endomorphy, mesomorphy and ectomorphy among female adolescent Hausa

\begin{tabular}{cccccrr}
\hline $\begin{array}{c}\text { Dependent } \\
\text { variable }\end{array}$ & $\begin{array}{c}\text { Wilks' } \\
\text { Lambda }\end{array}$ & $\mathrm{F}$ & $\mathrm{Df}$ & Sig. & $\begin{array}{c}\text { Noncent } \\
\text { parameter }\end{array}$ & $\begin{array}{c}\text { Observed } \\
\text { power }\end{array}$ \\
\hline Overral & 0.569 & $2.778^{*}$ & 40,806 & 0.001 & 96.044 & 1.000 \\
\hline Height $(\mathrm{cm})$ & - & $3.413^{*}$ & 8,188 & 0.001 & 27.301 & .975 \\
Weight $(\mathrm{cm})$ & - & $5.575^{*}$ & 8,188 & 0.001 & 44.599 & 1.000 \\
Endomorphy & - & $2.621^{*}$ & 8,188 & 0.010 & 20.968 & 0.917 \\
Mesomorphy & - & 1.353 & 8,188 & 0.220 & 10.828 & 0.608 \\
Ectomorphy & - & $3.338^{*}$ & 8,188 & 0.001 & 26.701 & 0.972 \\
\hline
\end{tabular}

$* P<0.05$

\section{DISCUSSION}

As a whole, the mean somatotype of the adolescent Hausa ethnic group of SabonGari L.G.A., Kaduna State was mesomorphectomorph (1.68-2.31-3.75) for males and central for females (3.10-2.23-3.29). When compared with age-matched samples of Andibila males and females of Benue State by Goon et al. (2013), whose mean somatotypes for male and female were found to be mesomorph-ectomorph (1.20-2.41-2.58) and mesomorph-ectomorph (1.36-2.16-2.67) respectively, adolescent Hausa are more endomorphic, ectomorphic and less mesomorphic. Similarly, Gaur et al. (2014) on the somatotype of Rajput adolescents in India found the mean somatotypes as a whole to be 3.45-2.48-4.63 (endomorphic-ectomorph) for girls and 1.61-3.20-4.38 (mesomorphicectomorph) for boys and these are dissimilar with the present studies. The somatotype of Chinese boys and girls was found to be ectomorphic mesomorph and central respectively (Ji and Ohsawa, 1996). The morphological variation seen may be attributable to some measure of genetic factors, nutrition, geographical location, physical activities, hormonal and other sociocultural or environmental factors.

In the present study, the female Hausa adolescents had a moderate endomorphic rating i.e., obese physique with large deposits of subcutaneous fat while the males on the other hand had a low rating, which implies marked lean physique with minimum subcutaneous fat.
This finding is consistent with the general understanding that females of the human species have more fatness overall than males (Pavlovsky andKobyliansky, 1997; Kalichman andKobyliansky, 2006). Girls tend to have more subcutaneous fat at all ages and the differences in fatness between boys and girls become more pronounced during adolescence (RoemmichandRogel, 1995; Rolland-Cachera, 1995; Jurimae andJurimae, 2001; Gaur et al., 2014). Traditionally, while the boys are performing physically demanding jobs like farming, cutting firewood and helping to rear domestic animals, the girls are often restricted to household chores, which require less physical activity. Additionally, it is possible that while the girls remain at home, they tend to eat more than the boys. These explanations, though nonempirical, should not be ignored as possible factors accounting for girls being more endomorphic compared to the boys (Goon et al., 2013). Hormonal influence (Gaur et al., 2014) is also a potential reason for the observed disparity.

The Hausa males and females had low mesomorphic ratings which were not significantly different. This denotes small bone and muscle mass plus small bone diameters relative to stature. The implication of these is that both Hausa boys and girls may be less involved in recreational games associated with high levels of physical activity, and less activity tends to disfavour musculoskeletal development (mesomorphy). 
BAJOPAS Volume 12 Number 1, June, 2019

This is incongruent with the general pattern of boys having greater average muscle mass at all ages than girls (Roemmich andRogel, 1995; Rolland-Cachera, 1995; Malinaet al., 2005; Arceet al., 2012; Gaur et al., 2014).

Similarly, the ectomorphic ratings in both sexes were a moderate one, though males are significantly more ectomorphic than the females. This characterizes them as having little mass relative to stature plus relatively elongated limb segments. However, according to Carter and Heath (1990), there are fewer differences in general in ectomorphy between males and females. Rebatoet al. (1996) noted that in a sample of Basque boys and girls, ectomorphy values were closer in both sexes compared with the other two components, with higher mean values for males. Several other researchers also found no difference in ectomorphy between boys and girls (Kalichman andKobyliansky, 2006; Gaur et al., 2008, 2014). The disparity in the results of our study with other reports could stem from ethnic differences, genetics, nutrition, hormonal and environmental influence, type of study and methodological inconsistencies.

In general, males are more mesomorphic, slightly more ectomorphic, and less endomorphic than females, from preschool ages through to young adulthood (Malina, 2004). Variations in various components during adolescence can be translated in terms of growth and development in humans that characterize changes in size and shape relative to time (Cameron, 2012).

The one-way MANOVA analysis indicated a significant effect of age on mean somatotypes in boys, as well as in girls. Also, the F-test did show significant age differences in the dominant mesomorphy in males and dominant endormorphy and ectomorphy in females. In congruence with the present findings, some studies have shown significant changes in component dominance in both sexes during growth from early to late adolescence (Rebatoet al., 1996; Tamazo-Ravnik, 1996; Hebbelincket al., 2005)). Also, in a recent study by Gaur et al. (2014) on Indian children and adolescents, the instability of somatotype was also demonstrated. However, several other researchers reported no significant changes in component dominance during growth (Claessenset al., 1986; Bhasinand Singh, 1991; Singh and Singh, 2006). Thus the evidence is still inconclusive and needs further exploration.

\section{CONCLUSION}

There were notable sex differences in the somatotypes of Hausa adolescents of Zaria, Nigeria, with girls being significantly more endomorphic and boys being more ectomorphic. Mesormorphy did not significantly differ between the sexes. In both sexes, the somatotypes (mesomorphy in males and endomorphy and ectomorphy in females) showed significant changes from early to late adolescence. More studies, especially longitudinal ones, are necessary to better understand somatotype variations during adolescence.

\section{Acknowledgments}

We deeply appreciate all the students and staff of the various schools in Zaria, Kaduna State for the cooperation offered us in carrying out this study.

\section{Financial Support and Sponsorship}

Nil.

\section{Conflicts of Interest}

There are no conflicts of interest.

Contributions of Authors

\begin{tabular}{lcccccc}
\hline Aurthors & Lit. Rev. & Methodology & Results & Discussion & Conclusion & References \\
\hline Mustapha M & $\checkmark$ & $\checkmark$ & $\checkmark$ & $\checkmark$ & $\checkmark$ & $\checkmark$ \\
Adamu AA & & $\checkmark$ & $\checkmark$ & & $\checkmark$ \\
Dahiru AU & & & & & \\
Maryam M & $\checkmark$ & $\checkmark$ & & & \\
\hline
\end{tabular}

\section{REFERENCES}

Arce, P.L., Flores, A.A., Lelievre, C.S., Marincovic, D.I., Gutierrez, O.B., and de la Rosa, F.B., (2012). Changes of Somatotype in High School Students, V Region, Chile: 1985-2010. Nutrition Hospital, 27, 270-275.

Bhasin, M.K., and Jain, S. (2007). Biology of the tribal groups of rajasthan, India: Age changes in somatotype. Anthropologist, 9, 257-265.
Bhasin, M.K., and Singh, L.P. (1991). Somatotype Changes During Adolescence in Gujjars and Tibetans of Jammu and Kashmir, India.Journal of Human Ecology, 2, 81-84.

Cameron, N. (2012). The Human Growth Curve, Canalization and Catch Up Growth. In: N. Cameron, N., Bogin, B., (Eds), Human Growth and Development. Amesterdam, Academic Press, pp.1-22

Carter, J. E. L. (1996). Kinanthropometry, exercise, and sports-a review.African 
BAJOPAS Volume 12 Number 1, June, 2019 Journal of Physical Health Education and Recreational Dance, 2 (1), 89-101.

Carter, J. L. E., and Heath, B. H. (2002). Somatotyping development and applications, Cambridge University Press, Cambridge.

Carter, J.E.L., and Heath, B.H. (1990). Somatotyping: development and applications. New York: Cambridge University Press.

Carter, J.L.E., and Heath, B.H. (2002). Somatotyping development and applications.Cambridge,UniversityPress, Cambridge.

Choi, J. W., Choe, H. W., andPai, S. P. (2003). Serum lipid concentrations correlate more strongly with total body fat that with body mass index in obese humans. Clinical Acta, 329, 83-87.

Claessens, A.L., Beunen, G., andMalina, R.M. (2000). Anthropometry, Physique, Body Composition and Maturity. In: Amstrong, N., Van Machelen, W., (Eds.), Paediatric Exercise Science and Medicine Oxford, Oxford University Press, pp. 11-22.

Claessens, A.L., Beunen, G., and Simons, J. (1986). Stability of anthroposcopic and anthropometric estimatesof physiques in Belgian boys followed longitudinally from 13 to 18 years of age. Annals of Human Biology, 13, 235-244.

Cressie, N.A.C., Withers, R.T., and Craig, N.P. (1986). The statistical analysis of somatotype data.Yearbook Physical Anthropology, 29, 197-208.

Gakhar, I., and Malik, S.L. (2002). Age changes and sex differences in somatotypes among jats of delhi. Anthropologist, (Special Issue), 1, 115-125.

Gaur, R., Maurya, M., and Kang, P.S. (2008). Sex, Age and Caste Differences in Somatotypes of Rajput and Scheduled Caste Adolescents from Sirmour District of Himachal Pradesh, India. Anthropology Anz, 66, 81-97.

Gaur, R., Talwar, I.D.I., and Negi, V. (2014). Age and Sex Variations in the Somatotypes ofRajput Adolescents of the Kullu District of the Himachal Pradesh Province, North India. International Journal of Anthropology, 29, 227-244.

Goon, D.T., Amusa, L.O., Shaw, B.S., Shaw, I. andAkusu, S.W. (2013). Somatotypes of Andibila children aged 7 to 14 years in Oju,Nigeria. African Journal for Physical, Health Education, Recreation and Dance (AJPHERD),19, 1037-1046.
Hebbelinck, M., Duquet, W., Jan Borms, J., and Carter, J.E.L. (2005). Stability of Somatotypes: A Longitudinal Study of Belgian Children Age 6 to 17 Years. American Journal of Human Biology, 7, 575- 588.

International Society for the Advancement of Kinanthropometry, (2001). International Standards for Anthropometric Assessment, The University of South Australia Holbrooks Rd, Underdale, SA, Australia.

Ji, C., andOhsawa, S. (1996). Changes in Somatotype During Growth in Chinese Youth 7-18 Years of Age. American Journal of Human Biology,8, 347-359..

Jurimae, T., andJurimae, J., (2001). Physical Activity and Motor Development in Prepubertal Children. Boca Raton, CRS Press.

Kalichman, L., andKobyliansky, E. (2006). Sexand age-related variations of the somatotype in a chuvasha population. Journal of Comparative Human Biology, 57, 151-162.

Liiv, H., Wyon, M., Jurimae, T., Purge, P., Saar, M., Maestu, J., andJurima, J. (2013). Anthropometry and somatotypes of competitive dance sport participants: a comparison of three different styles. Journal of Comparative Human Biology, 65, 155-160.

Malina, R.M., Bouchard, C., and Bar-Or, O., (2004). Growth, Maturation and Physical Activity (2Edition) Champaign, IL: Human Kinetics

Malina, R.M., Bouchard, C., andBeunen, C. (2005). Human Growth: Selected Aspects of Current Research on WellNourished Children. Annals of Revised Anthropology, 17,187-201.

National Population Commission, (2006). National population census. Federal Republic of Nigeria Official Gazette, 96 (2).

Ozener, B., andDuyar, I. (2008). The effect of labour on somatotype of males during the adolescent growth period. Journal of Comparative Human Biology, 59, 161172.

Parizkova, J., and Carter, J.E.L. (1976). Influence of Physical Activity on Stability of Somatotype in Boys. American Journal of Physical Anthropology, 44, 327-340.

Pavlovsky, O., andKobyliansky, E. (1997). Population Biology of Human Aging. Angelo PontecoroboliEditore, Publishing House, Firenze, Italy 
BAJOPAS Volume 12 Number 1, June, 2019

Quickbird, (2015). QuikbirdSatelite Sensor/ Satelite Imaging Corp. Retrieved from: https://www.satimagingcorp.com

Rahmawati, T.N., Hastuti, J., and Ashizawa, K. (2004). Growth and somatotype of urban and rural Javanese children in Yogyakarta and Bantul.Indonesia. Anthropological Science, 112, 99-108.

Rebato, E., Rosique, J., andApraiz, A.G. (1996). Somatotypes of 14 to 19 year old urban boys and girls from Bilbao (Basque Country). Anthropology Anz, 54, 135147.

Reis, V.M., Machado, J.V., Fortes, M.S., Fernandes, P.R., Silva, A.J., Dantas, P.S., andFilho, J.F., (2007). Evidence for higher heritability of somatotype compared to body mass indexin female twins. Journal of Physiological Anthropology, 26, 9-14

Roemmich, J.N., andRogel, A.D. (1995). Physiology of Growth and Development.Its Relationship to Performance in the Young Athletes. Clinical Nutrition and Sports Medicine, 14, 483-502.
Rolland-Cachera, M.F. (1995). Prediction of Adult Body Composition from Infant and Child Measurements. In: Davis, P.S., Cole, T.J., (Eds.), Body Composition Techniques in Health and Disease, Cambridge: Cambridge University Press, pp 100-105

Singh, A. P., and Singh, S. P. (2006). Somatotopic variations: an analysis of some traditional occupations.Journal of Human Ecology, 19 (4), 249-251.

Tamazo-Ravnik, T., (1996). Juvenile Somatotypes in Slovenia. In: B.E. Bodzsar, B.E., Susanne, C., (Eds.), Studies in Human Biology,Budapest, Eotvos University Press, pp 335-34.

Toselli, S., Graziani, F., andGruppioni, G. (1997). Relationship Between Somatotype and Blood Pressure in Children Aged 6 to 14 Years. Acta. Medicine Auxology, 29, 143-148.

World Health Organisation (WHO), (2015). .Adolescent Health. Retrieved from: http://www.who.int/topics/adolescent health/en/ 